\title{
THE TRAINING OF LANGUAGE AND CONCEPTUAL THINKING IN THE CHILD WITH BRAIN DAMAGE \\ By ISAAC JOLLES
}

South Suburban Public School Co-operative Association of Cook County Hart School, Homewood, Illinois

One of the most perplexing problems to the teacher of educable mentally handicapped children is the pupil who responds readily to the nonacademic program but who fails to make satis. factory growth in the reading activity. This problem confronts the teacher of brain-injured children whose intelligence level is well within the normal range. Although this has not been definitely established through medical diagnosis, we have reason to believe that the inability of these children to comprehend oral instructions and/or to express their thoughts adequately is the direct result of some neurological impairment.

Before proceeding further with this discussion, a description of the type of child with whom we are concerned in this paper is in order. The most outstanding trait is the marked discrepancy between the IQ's obtained on verbal and nonverbal tests of intelligence with the performance on the non-verbal test being superior. For example, in classes for children of normal intelligence one may find a pupil whose Stanford-Binet (verbal) IQ is 85 but whose Arthur (non-verbal) IQ is 119. In special classes for the educable mentally handioapped one may find a pupil whose Standford-Binet IQ is 69 but whose Arthur IQ is 103 .

In either case the classroom manifestation of this difference, in verbal and non-verbal abilities is the same, namely, slow progress in academic work (particularly reading) but quite adequate progress in those activities which do not require dealing with symbols, abstractions, and conceptual thinking. Among the mentally deficient this type of child is prevalent enough to have caused the misconception among educators that the mentally handicapped are good with their hands but no good at "book learning." So much of one's intellectual functioning is dependent upon language that it is to be expected that this would bo frequently associated with mental retardation.

The writer has made a crude study of the effectiveness of the children's primary sensory channels for learning in the classroom (auditory, visual, and kinesthetic.) This study involved an analysis of the children's response to various types of intelligence test items and the correlation of the successes and failures with the three sense modalities mentioned above. The children involved in this study were 69 pupils who were in special classes for the educable mentally handicapped. It was found that the children who presented symptoms of language deficiency were inefficient in their responses to test items involving auditory stimulation whereas those who manifested no such symptoms seemed to be relatively adequate in their responses to items involving auditory stimulation.

Such a discovery should not surprise us, for it is obvious (as we have learned from the language development problems of deaf children) that language development depends so much upon a child's responsiveness to the spoken language of others. It should follow, then, that if the child has some neurological impairment which results in an inefficient auditory sensory channel, his language development will be retarded. Likewise, his ability to form concepts will be impaired, for conceptual thinking is dependent upon abstract thinking through the use of language symbols. Without language one cannot think in abstract terms; without abstraction it is most difficult to form concepts. We in North America learn about Africa through some one else's experience, not by going there ourselves. This we can do through language. The child with a serious language deficiency cannot learn about other continents effectively through the experience of others. We should not be surprised, then, when a child of this type replies to the question, "Where is Chile?", by saying, "In a can." Likewise, he is unable to express the similarity between a plum and a peach, but he probably could see some relationship between them if they were actually within his presence.

Our problem is how to reach this type of child so that he can learn to think and to read with comprehension, at least within the limits of his intellectual potential. As far as this writer has been able to learn, there are no publications of research that would give information to a teacher on how to train such a pupil to form concepts. Therefore, the writer collaborated with Miss Selma I. Southwick, teacher of educable mentally handicapped children in the Quincy, Illinois, Public Schools in the development of an 
instructional approach and a teaching sequence which we believe will be useful in achieving our goal. This method has been used by Miss Southwick during the past two years. In some of the cases progress has been unexpectedly good, in others somewhat slow. At least in most pupils we have observed progress beyond that which we have seen in the past.

The approach which -we are using involves intensive training in the forming of concepts. The part that language development plays in this approach will be evident in the description of the teaching sequence which has been broken down into the following steps.

1. Teaching the relationship of objects within the immediate experience of the pupil. The normal child accomplishes this step in his development through the use of a readiness work book; he checks objects which differ but in some way are alike and relate to each other. This relatively abstract approach (workbook pictures) is adequate for him because of his accurate interpretation of his environment, but in the case of the child with brain damage, be he mentally handicapped or normal in intelligence, this is not the case. He usually has a perceptual disorder which tends to make it difficult for him to interpret his environment accurately. In the usual workbook, he may not check the objects correctly; but, if he does check accurately, he cannot cxplain why he chose as he did. Such an achievement is mechanical and cannot be interpreted as an indication of readiness for academic work. Before using a workbook, this child needs a prolonged period of training wherein he has actual objects to manipulate. Thus, he can feel likenesses and differences in form, in texture and in function; he makes use of his relatively efficient visual and kinesthetic sensory channels. The objects need to be distinct in color, in form, and in function so that discrimination may be achieved more accurately. The color of the object must be in reasonably sharp contrast from its background. It's size must neither be so large that it completely obliterates the background (thus losing much of its perspective within the environment to the point of losing much of its meaning) nor so small that it becomes lost within the total field.

The child needs to verbalize as he manipulates, for by so doing he employs his auditory sense to emphasize what he is experiencing visually and kinesthetically. This is most important in that it helps to develop the effectiveness of his auditory sense modality. Verbalizing the experience not only increases the meaning of the experience for the child', but it a'Iso offers the teacher an opportunity to develop and to check the accuracy of the child's understanding of the particular situation. For example, in answer to the question: "How is the orange like the apple?" the child

\title{
With the compliments of
}

\section{GALLO (AFRICA) LIMITED}

\author{
Distributors of
}

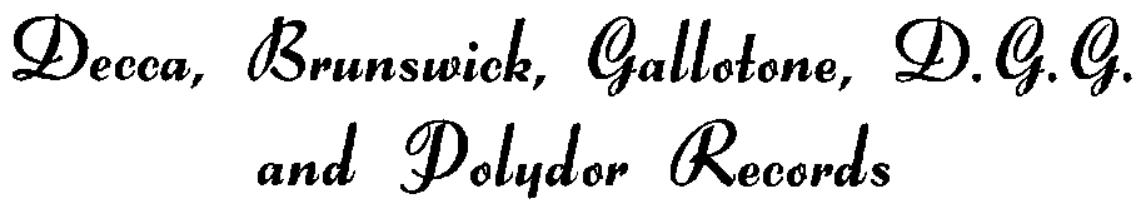


may say, "Because the orange is an orange."

2. Teaching the relationship of pictures of the above objects. The normal child effectively discriminates between the small pictures found in most readiness workbooks. The child with dis. orders in the language and concept areas may find it more meaningful to sort large, clearly defined pictures, for they help to compensate for his perceptual disability. Here again the actual manipulation of the pictures tends to center his attention to a degree that more accurate interpretation is achieved.

3. Drill on the relationship of pictures of objects not within the immediate experience of the child. All teachers are well aware of the value of pictures in extending the child's understanding of the world beyond his immediate environment. The normal child looks at the pictures, discriminates, and evaluates the messages presented, particularly as it relates to his past experiences. This is not true for the child with a concept disorder. For example, suppose the teacher presents the following pictures for study:

1. A person lying on a sofa.

2. A person sleeping in a bed.

3. A person sitting quietly under a shady tree.

4. Persons playing baskethall.

5. A person operating a machine in a factory.

The child unable to form good concepts will find it difficult to understand why all the pictures except the last denote some kind of rest or

relaxation. This child need's extensive opportunity to study pictures that have very distinct messages. As he discusses the pictures the teacher helps him to clarify his thinking by interjecting questions which help him to work out an accurate interpretation. For example, the child responds with "The orange is an orange," to the question stated above. The teacher then directs his thinking as follows:

"Yes, an orange is an orange. Is an orange round like a ball? Is an apple round like a ball? Can you eat an orange? Can you eat an apple? Can you eat a ball?"

The teacher will note the similarity of this exercise to exercises in the traditional workbook. There are, however, important differences for the child we are discussing. This child must have concrete experiences in order to observe simikarity, i.e., actual fruits if they are available, sharply defined pictures as a second best visual aid. The child works out his reasoning orally so that he hears his sequence of ideas which give him the correct concept regarding the apple and the orange.

4. Teaching to transfer this type of thinking to other situations.

5. Teaching the relationship between words, pictures and objects with stress being placed on

\section{PRETORIA SCHOOL FOR CEREBRAL PALSY}

\author{
P.O. BOX 1511, PRETORIA.
}

Applications are invited for the post of Speech Therapist

SALARY: (4 Year Course) $£ 600 \times 30-£ 960$

Four school holidays annually.

TO ASSUME DUTIES AS SOON AS POSSIBLE.

Apply: THE PRINCIPAL, P.O. Box 1511, PRETORIA.

the meaning of words.

6. Drill on the forming of concepts with words without the aid of objects and pictures.

7. Redrill on the transfer of this training to other situations.

Steps 4 through 7 of the developmental sequence follow the methods suggested above for steps 1 through 3. Each problem which the child confronts must require a choice of solutions with the necessary reasoning involved in making the choice. For example, phonetic instruction in reading is of little value unless the child is required to transfer the learning of the drill period to actual reading situations that are meaningful to him. If he has learned the short sound of "a", then he should have to face an unknown word which is controlled by this sound so that the teacher will see that he applies his new learning correctly in order to help him pronounce this word.

In conclusion, the type of child whom we have been discussing here must start slowly with a simple experience which is so very concrete that he can see it, hear it, manipulate it to the degree necessary to prove to himself its actual reality. For this reason we must adhere to the sequence mentioned above in the training of oncepts as well as in the development of language itself. In other words, we start with the concrete objects, go on to pictures, then to the word, and finally to the printed word which is the ultimate in symbolism. 